\title{
A EDUCAÇÃO AMBIENTAL APRESENTADA NA BNCC E NO PCN: UMA BREVE ANÁLISE
}

\author{
BÁRBARA MITSUKO ZUKERAM FUJIOKA* \\ LUCIANA APARECIDA NOGUEIRA DA CRUZ** \\ EDILSON MOREIRA DE OLIVEIRA***
}

\begin{abstract}
RESUMO
O presente artigo tem por objetivo analisar como os conteúdos de ciências de documentos curriculares brasileiros propõem o desenvolvimento da Educação Ambiental e da cidadania. Os documentos pesquisados foram os Parâmetros Curriculares Nacionais para o Terceiro Ciclo do Ensino Fundamental e a Base Nacional Comum Curricular para o sexto e sétimo ano do Ensino Fundamental. Utilizando a abordagem qualitativa, foi feita a seleção de trechos relacionados a temática ambiental e posterior análise crítica desses. Os resultados indicam que os documentos pouco contribuem para a Educação Ambiental, pois eles se restringem em propor uma abordagem sistematizada, vaga e conteudista desta. Dessa forma, pouco se oportuniza aos estudantes o desenvolvimento da cidadania, ou seja, a experiência e o entendimento de que as práticas sociais, desenvolvidas cole-
\end{abstract}

* É licenciada em Ciências Biológicas no Instituto de "Biociências, Letras e Ciências Exatas” da UNESP, câmpus de São José do Rio Preto (IBILCE/ UNESP). Contato: mitsuko.fujioka@,unesp.br

** É professora adjunta do Departamento de Educação e do Programa de Pós-Graduação em Ensino e Processos Formativos do Instituto de "Biociências, Letras e Ciências Exatas" da UNESP, campus de São José do Rio Preto (IBILCE/UNESP).

*** É Professor Assistente Doutor II do Departamento de Educação e do Programa de Pós-Graduação em Ensino e Processos Formativos do Instituto de "Biociências, Letras e Ciências Exatas" da UNESP, câmpus de São José do Rio Preto (IBILCE/UNESP).

Cadernos de Educação, v.20, n. 40, jan.-jun. 2021 
tivamente, são o que efetivamente contribuem para a construção de uma sociedade mais justa e mais sustentável. Concluindo, os conteúdos de ciências de ambos os documentos se apresentam como uma forma de desenvolver trabalhadores que reproduzem o modelo de sociedade atual que é pautada na desigualdade e na exploração e desvalorização do meio ambiente.

Palavras chave: Educação Ambiental; cidadania; meio ambiente; Parâmetros Curriculares Nacionais; BNCC.

\begin{abstract}
This qualitative research aims to analyze how the science of Brazilian curricular documents propose the development of Environmental Education and citizenship. The documents searched were the National Curricular Parameters of the Third Cycle of Elementary Education and the Nacional Common Curricular Base of the sixth and seventh grade of Elementary Education. It was selected sections related to the environmental theme, followed by their subsequent critical analysis. The results indicate a small contribution of the documents to the Environmental Education, because they restrict themselves to proposing a systematic, vague and contented approach. Thus, students are not given the opportunity to develop citizenship, that is, the experience and understanding that social practices, developed collectively, are what effectively contribute to the construction of a more just and more sustainable society. In conclusion, the science of both documents is presented as a way of developing workers who reproduce the current model of society, that is guided by inequality and the exploitation and devaluation of the environment.
\end{abstract}

Keywords: Environmental Education; citizenship; environment; National Curricular Parameters; BNCC. 


\section{INTRODUÇÃO}

Com o passar do tempo, o homem começa a atuar na transformação do meio ambiente. Atuação essa que se torna mais intensa nos séculos XIX e XX, gerando profundos desequilíbrios e problemas ambientais. Por essa razão, é necessário pensar ações que influenciem diretamente a continuidade e a qualidade da vida no planeta (SANTINELO et al., 2016). A crise ambiental relaciona-se com questões sanitárias e econômicas, com a qualidade de vida e com o empobrecimento da qualidade das relações sociais. Além disso, observamos a imposição das ideias neoliberais, que possuem, como prioridade, o mercado na tomada de decisões referentes à sociedade (OLIVEIRA, 2018). Com a vivência de uma crise socioambiental e informações sobre suas consequências para o planeta, a Educação Ambiental apresenta-se como uma das soluções possíveis para o enfrentamento dessas questões (GUIMARÃES et al., 2009).

A Educação Ambiental desenvolve-se, conjuntamente com a preocupação sobre os impactos ambientais e sobre a intensificação de estudos sobre Ecologia, em meados dos anos de 1950. Nos anos de 1960, a questão ambiental passa a abranger áreas, para além da científica, por conta dos conflitos bélicos, do uso de energia nuclear e da fome mundial. Sumariamente, esses fatores culminaram no Clube de Roma, em 1968, cuja origem se deu após um encontro com 30 pessoas, de diferentes profissões e oriundas de 10 países. Esse encontro apresenta, em suas conclusões, os limites para o desenvolvimento socioeconômico da humanidade, quais sejam: população, produção agrícola, recursos naturais, produção industrial e poluição (AMARAL, 2001).

A Conferência das Nações Unidas sobre o Meio Ambiente Humano, ou a Conferência de Estocolmo de 1972, foi a primeira conferência global sobre o Meio Ambiente. Nela, há o primeiro balanço dos impactos ambientais causados pelos seres humanos, abordando pontos para o desafio de preservar e de melhorar o meio ambiente. Como resultado, surge a Declaração de Esto- 
colmo, na qual se defende, principalmente, metas e objetivos quanto às políticas ambientais (HANDL, 2012).

Em 1992, no Rio Janeiro, a Conferência das Nações Unidas sobre Meio Ambiente e Desenvolvimento (UNCED), a segunda global sobre o meio ambiente, culmina na Agenda 21. Nessa época, a tarefa da comunidade internacional era posicionar-se de forma legalizada e política em relação ao meio ambiente, além de sistematizar e de estabelecer expectativas acerca dele. Esperava-se que a UNCED resultasse em uma Carta da Terra, um documento legal, no qual seriam apresentados os direitos e os deveres para com o meio ambiente e o desenvolvimento. A Declaração do Rio, considerada o marco principal do meio ambiente (HANDL, 2012), baseia-se na e reafirma a Declaração de Estocolmo.

Dez anos depois da Rio-92, a Organização das Nações Unidas (ONU) realizou a Conferência das Nações Unidas sobre Ambiente e Desenvolvimento Sustentável, em Johanesburgo, África do Sul, denominada Rio +10 . O evento voltava-se, principalmente, para pautas sociais, com o objetivo de adotar um plano de ação sobre pobreza, consumo, gestão de recursos naturais, direitos humanos, entre outros temas relevantes. Além disso, durante os debates foram revistas as metas da Agenda 21, com enfoque nas áreas que necessitariam de maior esforço para sua implementação, a partir de um plano de ação global; procurando gerenciar o desenvolvimento da sociedade com a preservação do meio ambiente (BRASIL, 2012).

Marcando os vinte anos da realização da Conferência das Nações Unidas sobre Meio Ambiente e Desenvolvimento, a última conferência global realizada pela ONU aconteceu em 2012 no Rio de Janeiro, e foi denominada Conferência das Nações Unidas sobre Desenvolvimento Sustentável, a Conferência Rio+20. Objetivou a renovação do compromisso com o desenvolvimento sustentável, avaliando o andamento da implementação das medidas adotadas anteriormente e tratando de temas novos e emergentes, a saber: (i) a economia verde no contexto 
do desenvolvimento sustentável e da erradicação da pobreza e (ii) a estrutura institucional para o desenvolvimento sustentável (RIO+20, 2012).

Para a construção de novos padrões de consumo de indivíduos mais conscientes da importância da preservação do planeta, a educação apresenta-se como um caminho. Construção essa que deve se dar por meio da obtenção de novos valores no desenvolvimento de uma sociedade democrática e socialmente justa (GOMES, 2006). Em se tratando da Educação Ambiental, Carvalho (2001) considera três dimensões relacionadas ao desenvolvimento de suas atividades e a formação de professores. A primeira dimensão, da natureza dos conhecimentos, direciona-se à classificação e à descrição dos elementos, dos fenômenos e dos processos naturais, sem considerar a integração entre eles. Ainda segundo o autor, ambientalistas têm considerado a necessidade de relacionar o homem organizado em sociedade com a natureza, abarcando outros aspectos, como, por exemplo, economia, política, sociedade e tecnologia. $\mathrm{Na}$ segunda dimensão, a dos valores éticos e estéticos, o aspecto ético está associado a atividades que sensibilizam os cidadãos frente aos valores estéticos da natureza e da própria ciência, permitindo, também, a vivência desses. Por fim, a terceira dimensão, chamada de dimensão política, refere-se à procura por possíveis caminhos para solucionar os problemas ambientais por meio da participação coletiva dos indivíduos (CARVALHO, 2001). Nesse cotejo, a Educação Ambiental é uma realização humana e apresenta-se como um ato político, caracterizando-se em uma sociedade de classe como um caráter reprodutor/transformador (OLIVEIRA, 2018).

A Lei n. 9.795, de 27 de abril de 1999, dispõe sobre a Educação Ambiental, instituindo uma Política Nacional de Educação Ambiental, conforme consta em seu artigo $1^{\circ}$ :

[...] entendem-se por educação ambiental os processos por meio dos quais o indivíduo e a coletividade constroem 
valores sociais, conhecimentos, habilidades, atitudes e competências voltadas para a conservação do meio ambiente, bem de uso comum do povo, essencial à sadia qualidade de vida e sua sustentabilidade (BRASIL, 1999).

$\mathrm{O}$ artigo $2^{\circ}$ define a Educação Ambiental como um componente essencial da educação brasileira, devendo estar presente, de forma permanente e articulada, em todo o processo educativo, e, conforme disposto no artigo $3^{\circ}$, ser igualmente ofertada a todos. Ainda segundo o inciso I, do artigo $3^{\circ}$, o Poder Público deve ser incumbido de não só promover a Educação Ambiental, mas, também, o engajamento da sociedade na conservação, na recuperação e na melhoria do meio ambiente (BRASIL, 1999).

De acordo com a Constituição Federal de 1988, os conteúdos relacionados à Educação Ambiental devem ser desenvolvidos de forma complexa, levando em conta a dinâmica das ações e das reações (SANTINELO et al., 2016). Aos educadores, cabe-lhes a responsabilidade de despertar em seus alunos a confiança em seu próprio potencial, partindo da premissa de que todos os indivíduos podem contribuir, efetivamente, para a melhoria do planeta. A crença em si próprio pode despertar um engajamento no exercício da cidadania, resultando em mudanças na sociedade frente a questões socioambientais (PÁDUA, 2000). É importante haver uma base curricular clara e concreta para que a Educação Ambiental ocorra, efetivamente, e que seja desenvolvida em todas as áreas do conhecimento, não somente na área de Ciências da Natureza, como, historicamente, vem ocorrendo (SANTINELO et al., 2016).

Devemos considerar a elaboração de programas de ensino, de guias e de propostas curriculares como uma prática frequente nos governos. Prática essa que influencia, diretamente, a educação, uma vez que esses documentos são utilizados como aportes para a elaboração de materiais didáticos, além de direcionarem a formação continuada de professores e de serem indicadores 
da constituição do campo pedagógico de determinado período (SOUZA et al., 1999).

Entendendo a importância dos conteúdos curriculares para o desenvolvimento da Educação Ambiental nas escolas, o objetivo deste artigo é analisar documentos brasileiros, utilizados como guias curriculares no Brasil. O objetivo da análise é responder o seguinte conjunto de questões. (i ) O conteúdo de ciências presente nos guias curriculares selecionados oferece suporte necessário para o desenvolvimento de indivíduos politicamente, ativos e transformadores da sociedade? (ii) O conteúdo de ciências presente nos guias curriculares selecionados oferece suporte necessário para a implementação da Educação Ambiental por parte dos docentes? (iii) É possivel fazer conexões entre os conteúdos relacionados à Educação Ambiental nos dois documentos? Caso sim, esses são abordados da mesma forma em ambos? (iv) A Base Nacional Comum Curricular apresenta-se de acordo com o que preveem os Parâmetros Curriculares Nacionais?

Com esses questionamentos, buscamos investigar como os guias curriculares direcionam a abordagem do conteúdo de Educação Ambiental nos documentos selecionados, observando se esse conteúdo realmente contribui para a realização da Educação Ambiental e, consequentemente, para a formação cidadã efetiva dos estudantes.

\section{DETALHAMENTO METODOLÓGICO}

A técnica mais indicada para uma pesquisa documental é a análise de conteúdo, cujo principal objetivo é revelar sentidos ocultos ou aparentes de um texto ou de um documento por meio de um estudo aprofundado de partes desses (TOZONI-REIS, 2009). A pesquisa foi realizada com abordagem qualitativa, caracterizada pelo entendimento e pela explicação de dinâmicas das relações sociais, considerando pontos da realidade que não podem ser quantificados (GERHARDT; SILVEIRA, 2009).

Dessa forma, este trabalho desenvolveu-se por meio da análise do conteúdo de Ciências Naturais de dois documentos 
específicos, quais sejam: (i) os Parâmetros Curriculares Nacionais (PCNs) para o Terceiro Ciclo do Ensino Fundamental (EF) e (ii) a Base Nacional Comum Curricular (BNCC) do EF, com enfoque nos sexto e sétimo anos.

Procedemos, então, a leitura integral dos documentos, a fim de obtermos o entendimento global de suas estruturas. Em seguida, realizamos a análise dos conteúdos presentes na segunda parte dos PCNs, referentes ao terceiro ciclo do EF, e a segunda parte da BNCC, referente aos sexto e sétimo anos do EF. A análise foi realizada considerando trechos dos documentos que fazem alguma menção ao meio ambiente, à Educação Ambiental e à cidadania. Em seguida, analisamos criticamente esses trechos, de modo a respondermos os questionamentos propostos neste artigo. Utilizamos, como referências, pesquisas similares a esta, para nos auxiliarem na interpretação e na discussão dos resultados.

\section{RESULTADOS E DISCUSSÃO}

Apresentamos, a seguir, os resultados da análise realizada dos conteúdos de Ciências Naturais dos PCNs, para o terceiro ciclo. De acordo com o documento, a partir do terceiro ciclo é possível que os alunos ampliem a participação no meio social, desenvolvendo atitudes críticas nas relações pessoais e em outros aspectos da vida afetiva e cultural. As aulas de Ciências podem envolver leituras de textos científicos, práticas com experimentos, observações, esquematizações, entre outras atividades que promovam o aprendizado. Portanto, é preciso que as aulas de Ciências envolvam mais do que simplesmente a memorização do conteúdo fora do contexto social, cultural e ambiental do aluno, que resultam somente em um aprendizado momentâneo (BRASIL, 1998).

Especificamente para o terceiro ciclo, os PCNs apontam o interesse especial em desenvolver atividades que envolvam participação oral, como, por exemplo: debates; dramatizações; entrevistas e exposições espontâneas ou preparadas; atividades em grupo voltadas para: experimentação, observação e reflexão. Entre essas atividades, aquelas de natureza lúdica, gestual e coletiva cumprem, ainda, a função de minimizar a ruptura, até mesmo, afetiva do regime de professor de turma. Nesse ciclo, é 
interessante abordar aspectos históricos das ciências, oferecendo informações para fomentar o debate sobre a relação entre ciência, tecnologia e sociedade (BRASIL, 1998).

Segundo o documento, no eixo temático Terra e Universo, a orientação espaço-temporal dos alunos pode ser aprofundada, bem como a conscientização dos ritmos de vida. No desenvolvimento dos conteúdos desse ciclo, as atividades de observação e de elaboração de explicações pelos próprios alunos é imprescindível. Já o eixo temático Vida e Ambiente busca proporcionar aos estudantes a ampliação de conhecimentos sobre os ambientes, seus problemas, os seres vivos, as condições para a vida e a compreensão do ambiente como um todo dinâmico. No eixo Ser Humano e Saúde, abordam-se a compreensão do corpo como um todo e a saúde humana integrada com aspectos orgânicos, ambientais, psíquicos e socioculturais, apresentando-a como dependente da situação política da comunidade e da nação. Por fim, no eixo temático Tecnologia e Sociedade, podem ser abordados os princípios operativos de equipamentos, aparelhos e sistemas. A partir de investigações os alunos podem identificar as diferentes tecnologias que permitem ou permitiram a realização de atividade humanas, como obtenção de alimentos e desenvolvimentos de transportes, a partir da transformação da matéria e da energia (BRASIL, 1998).

Os PCNs apresentam doze objetivos específicos para o ensino de ciências naturais no terceiro ciclo. Desses, podemos identificar três que podem ser relacionados com a temática ambiental, a saber: "valorizar a disseminação de informações socialmente relevantes aos membros da sua comunidade"; "valorizar a vida em sua diversidade e a conservação dos ambientes" e "interpretar situações de equilíbrio e desequilíbrio ambiental relacionando informações sobre a interferência do ser humano e a dinâmica das cadeias alimentares" (BRASIL, 1998, p. 60 e 61).

A seguir, apresentamos, resumidamente, os conteúdos propostos pelos PCNs para o ensino de Ciências Naturais no terceiro ciclo. Foram selecionados somente os conteúdos que possuem alguma relação com o meio ambiente, conforme ilustrado pelo Quadro 1. 
Quadro 1. Conteúdos relacionadas ao meio ambiente presentes nos PCNs de Ciências Naturais para o Terceiro Ciclo do Ensino Fundamental

\begin{tabular}{|c|c|}
\hline Unidade & Conteúdos \\
\hline Terra e Universo & $\begin{array}{l}\text { 1. Utilização da água para processos industriais e a po- } \\
\text { luição que essa utilização causa a mares, rios, solos e } \\
\text { fontes subterrâneas de água; } \\
\text { 2. Poluição do ar; } \\
\text { 3. Diminuição dos recursos naturais pelo uso exagerado, } \\
\text { inadvertido ou deliberado; } \\
\text { 4. Uso de alternativas naturais e tecnológicas para a } \\
\text { restauração do ambiente e seus custos. }\end{array}$ \\
\hline Vida e Ambiente & $\begin{array}{l}\text { 1. Problemas relacionados a alterações nas cadeias ali- } \\
\text { mentares. As relações entre populações e não somente } \\
\text { indivíduos; } \\
\text { 2. As alterações nas comunidades dos ambientes de- } \\
\text { correntes do controle de pragas, das queimadas, dos } \\
\text { desmatamentos, das poluições, entre outros; } \\
\text { 3. Construção das características dos ecossistemas } \\
\text { afetados pela ação humana. Realização de coleta, in- } \\
\text { terpretação organização e divulgação de informações } \\
\text { sobre esses ecossistemas; } \\
\text { 4. Caracterização das cadeias alimentares e outros pro- } \\
\text { cessos biológicos ao lado de investigações sobre a } \\
\text { ocupação humana; } \\
\text { 5. Desenvolvimento de medidas de recuperação e pro- } \\
\text { teção do meio ambiente; } \\
\text { Animais ameaçados de extinção e suas causas; } \\
\text { 7. Impacto das ocupações humanas no solo; } \\
\text { 8. Coleta, organização, interpretação e divulgação de infor- } \\
\text { mações sobre transformações nos ambientes provocadas } \\
\text { pela ação humana e medidas de proteção e recuperação. }\end{array}$ \\
\hline $\begin{array}{l}\text { Ser Humano e } \\
\text { Saúde }\end{array}$ & $\begin{array}{l}\text { 1. Consequências do uso de agrotóxicos na produção } \\
\text { de alimentos. }\end{array}$ \\
\hline $\begin{array}{l}\text { Sociedade e Tec- } \\
\text { nologia }\end{array}$ & $\begin{array}{l}\text { 1. Custos ambientais de diferentes fontes de energia, } \\
\text { dilapidação de recursos naturais. }\end{array}$ \\
\hline
\end{tabular}

Fonte: elaborado pelos autores.

Obs.: $\mathrm{Na}$ primeira coluna, consta o nome do eixo temático ao qual pertence cada conteúdo. Na coluna seguinte, consta a apresentação desses conteúdos, de forma sucinta. 
Apresentamos, a seguir, resultados da análise dos conteúdos de Ciências na BNCC, para os sexto e sétimo anos. No contexto dos anos finais do EF, é importante motivar os alunos com desafios, permitindo-lhes a formulação de questionamentos mais complexos e contextualizados. Quanto mais próximos do Ensino Médio (EM), mais os alunos conseguirão estabelecer relações aprofundadas entre ciência, tecnologia, natureza e sociedade. É fundamental que nesse momento os alunos sejam capazes de protagonizarem seus posicionamentos, valorizando o pessoal e o coletivo (BRASIL, 2018).

Nos anos finais do EF, a unidade temática Matéria e Energia é trabalhada a partir da exploração dos fenômenos envolvidos nas matérias e na energia e a partir da exploração do sistema produtivo e seus impactos no meio ambiente. O desenvolvimento desse conteúdo deve possibilitar aos alunos avaliar, por exemplo, a partir do conhecimento científico, vantagens e desvantagens da produção de produtos sintéticos, de combustíveis e de diferentes tipos de energia. Deve ser proporcionado aos alunos a reflexão sobre: hábitos mais sustentáveis no uso dos recursos naturais, na produção de novas tecnologias e no aproveitamento responsável dos recursos naturais (BRASIL, 2018).

$\mathrm{Na}$ unidade Vida e Evolução, desenvolvem-se temas relacionados à natureza e ao ser humano, compreendido como participante e como modificador dela. Procura-se, assim, evidenciar maneiras mais eficientes de utilizar os recursos naturais, procurando discutir as consequências do consumo excessivo e do descarte inadequado dos resíduos. Outros temas, também, são desenvolvidos, como a reprodução e a sexualidade humana, as condições de saúde, o saneamento básico, a qualidade do ar e as condições nutricionais da população brasileira (BRASIL, 2018).

Nos anos finais do EF, a unidade Terra e Universo foca o desenvolvimento de uma visão sistêmica e socioambiental do planeta, por meio do estudo do solo, dos ciclos biogeoquímicos e do clima, por exemplo. Além disso, o conhecimento espacial 
é ampliado e aprofundado, explorando, preferencialmente, os vários fenômenos envolvendo a Terra, a Lua e o Sol e a contraposição envolvida na visão geocêntrica e heliocêntrica do Sistema Solar. Assim, espera-se que, com os conteúdos dessa unidade, os alunos consigam refletir sobre a posição da Terra e do ser humano no Universo (BRASIL, 2018).

A BNCC defende que as aprendizagens fornecidas ofereçam condições para que os alunos desenvolvam dez competências gerais ao longo da Educação Básica, as quais resumem os direitos de aprendizagem e de desenvolvimento dos alunos, englobando conhecimentos (conceitos e procedimentos), habilidades (práticas, cognitivas e socioemocionais), atitudes e valores necessários para resolver situações complexas da vida cotidiana, exercer a cidadania e atuar no mundo do trabalho. Especificamente, a área de Ciências da Natureza, na BNCC, apresenta oito competências específicas, as quais expressam dez competências gerais. Conforme representado pelo Quadro 2, é possível identificar quatro competências (as de número 2, 4, 5 e 8) relacionadas ao meio ambiente.

Ainda na estrutura da BNCC, identificamos uma série de habilidades, que "[...] expressam as aprendizagens essenciais que devem ser asseguradas aos alunos nos diferentes contextos escolares" (BRASIL, 2018, p. 29), garantindo que desenvolvam as competências específicas de cada área. As habilidades são relacionadas a objetos de estudo (conteúdos, conceitos e processos), que, por sua, vez compõem as unidades temáticas de cada área específica.

No conteúdo de Ciências, o sexto ano apresenta 14 habilidades. Dessas, somente a habilidade 4 está relacionada ao meio ambiente. No sétimo ano, as habilidades 5, 13 e 14 podem, também, ser relacionadas com a temática, sendo que, no total, há 16 habilidades compondo esse ano escolar. No Quadro 3 é possível observar o conteúdo dessas habilidades, o ano e a unidade temática a que elas pertencem. 
Quadro 3. Habilidades relacionadas ao Meio Ambiente presentes na área de Ciências Naturais da BNCC nos Anos Finais do Ensino Fundamental.

\begin{tabular}{|c|c|l|}
\hline Unidade & Habilidades & \multicolumn{1}{c|}{ Descrição da Habilidade } \\
\hline $\begin{array}{c}\text { Matéria e } \\
\text { Energia }\end{array}$ & EF06CI04 & $\begin{array}{l}\text { Associar a produção de medicamentos e ou- } \\
\text { tros materiais sintéticos ao desenvolvimento } \\
\text { científico e tecnológico, reconhecendo bene- } \\
\text { fícios e avaliando impactos socioambientais }\end{array}$ \\
\hline $\begin{array}{c}\text { Matéria e } \\
\text { Energia }\end{array}$ & EF07CI05 & $\begin{array}{l}\text { Discutir o uso de diferentes tipos de com- } \\
\text { bustível e máquinas térmicas ao longo } \\
\text { do tempo, para avaliar avanços, questões } \\
\text { econômicas e problemas socioambientais } \\
\text { causados pela produção e uso desses mate- } \\
\text { riais e máquinas }\end{array}$ \\
\hline $\begin{array}{l}\text { Vida e Evo- } \\
\text { lução }\end{array}$ & EF07CI13 & $\begin{array}{l}\text { Descrever o mecanismo natural do efeito } \\
\text { estufa, seu papel fundamental para o desen- } \\
\text { volvimento da vida na Terra, discutir as ações } \\
\text { humanas responsáveis pelo seu aumento } \\
\text { artificial (queima dos combustíveis fósseis, } \\
\text { desmatamento, queimadas etc.) e selecionar } \\
\text { e implementar propostas para a reversão ou } \\
\text { controle desse quadro }\end{array}$ \\
\hline Terra e Uni- \\
verso
\end{tabular}

Fonte: elaborado pelos autores.

Obs: Na primeira coluna, consta a Unidade Temática a qual pertence cada habilidade. A segunda apresenta o nome da habilidade, sendo que as letras EF correspondem a Ensino Fundamental, os dois números seguintes o ano ao qual a habilidade pertence, as letras CI correspondem a Ciências e os dois números finais correspondem ao número da habilidade. Na última coluna, consta o conteúdo dessas.

Embasados nas informações apresentadas, discutiremos alguns aspectos dos PCNs e da BNCC. É importante deixar claro que os resultados apresentados são ou podem ser relacionados à 
temática ambiental, uma vez que o principal objetivo da pesquisa é entender como a área de Ciências nos dois documentos menciona a Educação Ambiental e, consequentemente, a formação para a cidadania.

Os PCNs apresentam o desenvolvimento da cidadania como um dos objetivos gerais para o EF, afirmando que "[...] garantir estudos sobre o ambiente onde vive o aluno é um recurso essencial à cidadania" (BRASIL, 1998). Contudo, quando analisados os objetivos específicos das Ciências Naturais, relacionados ao meio ambiente, o documento não faz nenhuma referência à cidadania, limitando-se a utilizar as palavras como valorizar e interpretar informações. Portanto, o documento não pressupõe que a cidadania envolve a promoção de mudanças na sociedade por meio do engajamento dos seus cidadãos. Tal comportamento pode ser observado, também, quando o documento aponta os conteúdos que devem ser trabalhados no EF.

Para Piassi (2011), uma das limitações da formação cidadã dos PCNs é colocar o aluno na posição de um sujeito que está sendo informado e alertado sobre questões, as quais deve investigar ou analisar, na posição de expectador. Essa limitação apresenta-se como um problema, uma vez que o aluno, conforme o próprio documento afirma, já é um cidadão e está inserido em um contexto sociocultural. Apenas criar conexões entre os conteúdos estudados e a vida real, apresenta-se como uma medida conteudista e, por isso, ineficiente para a promoção de reflexões e de ações sobre as práticas sociais. Um ensino pautado nas práticas sociais não pode se limitar a sistematizações, visto que, somente a compreensão dos mecanismos e dos processos que ocorrem no meio ambiente, não garante, necessariamente, a mudança de práticas (PIASSI, 2011).

Bonfim et al. (2013) apontam a ausência de maneiras concretas de se trabalhar a temática do Meio Ambiente nas escolas, limitando-se a apresentar os conteúdos, sem, contudo, apresentar situações nas quais os estudantes possam colocar em prática 
ações que promovam mudanças políticas. Os autores apontam que os conteúdos do meio ambiente acabam por serem desenvolvidos, exclusivamente, por meio de projetos eventuais nas escolas, o que não resulta na efetiva Educação Ambiental.

Em relação à $\mathrm{BNCC}$, observamos certas semelhanças com os PCNs. Santos e Ribeiro (2020) afirmam que a BNCC, especialmente no que se refere ao ensino de Ciências, deve ser vista como forma de desenvolver a cidadania, e não como uma das formas de reforçar a desigualdade social ao considerar a educação como a responsável pelo desenvolvimento econômico (SANTOS, RIBEIRO, 2020). A própria BNCC justifica o conteúdo do ensino de Ciências, com a finalidade de atuar no "[...] desenvolvimento da capacidade de atuação no e sobre o mundo, importante ao exercício pleno da cidadania" (BRASIL, 2018, p. 319). Contudo, na apresentação das competências específicas para essa área, não há nenhuma referência à cidadania ou às formas pelas quais o professor pode desenvolver os conteúdos de forma a implementar a Educação Ambiental, tampouco no que se refere ao uso dos eixos temáticos e as habilidades.

Em relação aos conteúdos a serem abordados no ensino de Ciências, há uma quantidade significativa de conteúdos que abordam os problemas ambientais, como, por exemplo, a poluição, as alterações nos ecossistemas, o uso desordenado dos recursos naturais, entre outros, conforme apresentado no Quadro 3. Contudo, o documento concentra-se em fazer com que os alunos se conscientizem sobre esses e entendam como ocorrem, sem promover a discussão aprofundada sobre as mudanças que precisam ser realizadas. Ademais, não se discute também o fato de que esses impactos ambientais são causados pelo modelo capitalista de organização da sociedade, a partir do qual se explora demasiadamente o meio ambiente e, em detrimento desse, valoriza-se o consumismo. Quanto às competências específicas da área de Ciências Naturais que se referem ao meio ambiente, não é abordada suficientemente a questão de desenvolvimento do 
pensamento crítico por parte dos alunos, restringindo-se apenas a citar a "colaboração para a construção de uma sociedade justa, democrática e inclusiva", "construção de argumentos", entre outros (BRASIL, 2018, p. 322).

Para Santos e Ribeiro (2020), os objetivos gerais da área de Ciências Naturais, na BNCC, corroboram com o que se espera de um aluno cientificamente alfabetizado. Contudo, na prática, esses objetivos são difíceis de serem alcançados com o ensino conteudista de Ciências. Além disso, a quantidade de conteúdos a serem trabalhados são incompatíveis com as duas aulas semanais disponíveis para os professores de Ciências, levando-se em consideração que as disciplinas de Língua Portuguesa e de Matemática têm assumido cada vez mais espaço na grade escolar (SANTOS, RIBEIRO, 2020).

Nas habilidades da BNCC, as possíveis intervenções para a solução de problemas ambientais ficam restritas à teoria, como a avaliação de impactos socioambientais, as discussões de propostas no âmbito individual e coletivo, e a seleção e a implementação de propostas sem considerar as questões políticas necessárias para que isso ocorra. A habilidade EF07CI13, por exemplo, refere-se ao efeito de estufa; todavia, não leva em consideração por exemplo o agronegócio, um dos grandes causadores do problema apresentado. Outra habilidade que deve ser citada é a EF07CI08.

Avaliar como os impactos provocados por catástrofes naturais ou mudanças nos componentes físicos, biológicos ou sociais de um ecossistema afetam suas populações, podendo ameaçar ou provocar a extinção de espécies, alteração de hábitos, migração etc (BRASIL, 2018, p. 345).

Essa habilidade defende que os estudantes devem avaliar impactos e mudanças no ecossistema e suas consequências, sem considerar que o ser humano faz parte do meio ambiente 
e possui grande responsabilidade nas mudanças citadas. Outro ponto a ser considerado é a realidade de cada aluno e a diversidade da sala de aula, pouco considerada na BNCC, uma vez que não apresenta em seu interior alternativas para que seja implementada, frente à grande desigualdade social presente no Brasil. Faz-se necessária para o exercício da cidadania que sejam tratados os problemas locais, próximos à realidade dos alunos.

Sobre a abordagem da Educação Ambiental na BNCC, Silva e Loureiro (2019) destacam a forma pontual com que é citada no documento: aparecendo somente uma vez e, depois, desaparecendo por completo, a que os autores chamam de sequestro da Educação Ambiental. Ressaltamos, ainda, que, segundo o que prevê a Constituição, a Educação Ambiental não deve apenas estar presente nos currículos, como, também, ser abordada de forma interdisciplinar. Santos e Ribeiro (2020) afirmam a

[...] necessidade de estimular situações interdisciplinares, de compreensão dos fenômenos (sócio)ambientais em suas múltiplas dimensões e determinações e de atuação de maneira crítica, criativa, coletiva e transformadora do mundo vivencial das crianças e jovens (SANTOS; RIBEIRO, 2020, p. 87).

Todavia, a BNCC apresenta a Educação Ambiental como se vê tradicionalmente: relacionada à ecologia e à sustentabilidade, sem considerar os aspectos sociais, éticos, econômicos, políticos, tecnológicos e culturais, essenciais para o exercício da cidadania (SILVA, LOUREIRO; 2019). Portanto, BNCC não aprofunda como os professores podem trabalhar a interdisciplinaridade, sendo que os conteúdos são apresentados de forma separada. Isto é, a BNCC não proporciona o efetivo desenvolvimento da Educação Ambiental.

Ao fim e ao cabo, cumpre ressaltar que a BNCC, assim como os PCNs contribuem, somente, para a abordagem de 
problemas ambientais da forma que já são desenvolvidos nas escolas, por meio da implementação de projetos esporádicos em datas específicas do ano. Ambos os documentos se concentram no entendimento dos problemas ambientais que vivenciamos, de forma vaga e descontextualizada, sem propor que os estudantes analisem criticamente essas questões e exercitem meios de mudá-las. Dessa forma, assim como outras pesquisas apontam, a BNCC e os PCNs contribuem para o neoliberalismo e para o desenvolvimento de trabalhadores que, apenas, reproduzem o modelo de sociedade atual, sem o criticar.

\section{CONSIDERAÇÕES FINAIS}

Buscando verificar a efetividade dos conteúdos de ciências dos PCNs e da BNCC no desenvolvimento da educação ambiental e da cidadania, e possíveis similaridades entre os dois documentos, notamos que ambos apresentam os conteúdos de forma conteudista e sistematizada, considerando pouco a interdisciplinaridade, a diversidade da sala de aula e os reais problemas que afetam o meio ambiente. Concluímos que os conteúdos dos PCNs e da BNCC são insuficientes e contribuem para um ensino de Ciências no qual os estudantes não experienciam novas formas de pensar e construir uma sociedade coletivamente, restringindo somente a reprodução e a adaptação à realidade neoliberal na qual estamos inseridos. Assim, a EA é voltada somente para as duas primeiras dimensões da Educação Ambiental: a dimensão dos conhecimentos e a dimensão dos valores éticos e estéticos, sem desenvolver a dimensão política e seu caráter transformador. A escola é um espaço fecundo para os estudantes iniciarem a experienciação e o exercício da cidadania, por isso é essencial que os documentos curriculares sejam pensados de forma a proporcionar a realização dessa experiência e exercício e contribuir para uma sociedade mais justa e igualitária, respeitosa com o meio ambiente. 


\section{REFERÊNCIAS}

AMARAL, I. A. Educação Ambiental e ensino de ciências: Uma história de controvérsias. Pro-posições, Campinas, v. 12, n. 1, p. 73-93, mar 2001.

BONFIM, A. M. et al. Parâmetros Curriculares Nacionais: Uma revisita aos temas transversais meio Ambiente e saúde. Trab. Educ. Saúde, Rio de Janeiro, v. 11 , n. 1 , p. $27-52$, jan/abr 2013.

BRASIL. Lei n. 9.795, de 27 de abril de 1999. Disponível em http://www. planalto.gov.br/ccivil_03/LEIS/L9795.htm. Acesso em 9 set 2020.

BRASIL. Ministério da Educação. Base Nacional Comum Curricular Histórico. Disponível em http://basenacionalcomum.mec.gov.br/historico. Acesso em 9 set 2020.

BRASIL. Ministério da Educação. Base Nacional Comum Curricular. 2018. Disponível em http://basenacionalcomum.mec.gov.br/images/BNCC_EI_ EF_110518_versaofinal_site.pdf. Acesso em 9 set 2020.

BRASIL. Ministério da Educação. Secretaria de Educação Fundamental. Parâmetros Curriculares Nacionais: Ciências Naturais. Brasília: MEC/SEF, 1998.

CARVAlHO, L. M. A Educação Ambiental e a formação de professores. In: VIANNA, L. P. (coord.). Panorama da Educação Ambiental no Ensino Fundamental. Brasília, MEC/SEF, 2001. p. 55-61.

GERHARDT, T. E.; SILVEIRA, D. T. Métodos de pesquisa. Porto Alegre: Editora da UFRGS, 2009.

GOMES, D. V. Educação para o consumo ético e sustentável. Revista Eletrônica de Mestrado em Educação Ambiental, Rio Grande, v.16, p. 18-31, jan/jun 2006.

GUIMARÃES, M. et al. Educadores ambientais nas escolas: as redes como estratégia. Cad. Cedes, Campinas, v. 29, n. 77, p. 49-62, jan/abr 2009.

HANDL, G. Declaration of the United Nations Conference on the Human Environment (Stockholm Declaration), 1972 and the Rio Declaration on Environment and Development, 1992. United Nations Audiovisual Library of International Law. Disponible in https://www.globalhealthrights. org/wp-content/uploads/2014/06/Stockholm-Declaration1.pdf. Access in 9 sept 2020 . 
OLIVEIRA, E. M. Temática ambiental, educação ambiental e ensino. Dos limites da lógica formal à necessidade da dialética. São Paulo: Paco, 2018.

PÁDUA, S. M. A. Educação ambiental: um caminho possível para mudanças. In: VIANNA, L. P. (coord.). Panorama da Educação Ambiental no Ensino Fundamental. Brasília, MEC/SEF, 2001. p. 77-80.

PIASSI, L. P. Educação científica no ensino fundamental: Os limites dos conceitos de cidadania e inclusão veiculados nos PCN. Ciência \& Educação, Bauru, v. 17, n. 4, p. 789-805, 2011.

RIO+20. Sobre a Rio+20. 2012. Disponível em http://www.rio20.gov.br/ sobre_a_rio_mais_20.html. Acesso em 9 set 2020.

SANTINELO, P. C. C; ROYER, M. R.; ZANATTA, S. C. Educação ambiental no contexto preliminar da Base Nacional Comum Curricular. Pedagog. Foco, Minas Gerais, v. 11, n. 6, p. 104-115, 2016.

SANTOS, A. R.; RIBEIRO, L. M. L. A Base Nacional Comum Curricular e suas implicações na proposta curricular de ciências naturais do estado do Acre. Horizontes - Revista de Educação, Dourados, v. 8, n. 15, p. 81-97, jan/jun 2020.

SENADO FEDERAL. Rio+10 Revisa Metas da Agenda 21. Em Discussão, Brasília, ano 3, n. 11, p. 16, jun 2012. Disponível em https://www.senado.gov. br/NOTICIAS/JORNAL/EMDISCUSSAO/upload/201202\%20-\%20maio/ pdf/em\%20discuss\%C3\%A3o!_maio_2012_internet.pdf. Acesso em 9 set 2020.

SILVA, S. N.; LOUREIRO, C. F. B. O sequestro da educação ambiental na BNCC (educação infantil - ensino fundamental): os temas sustentabilidade/ sustentável a partir da Agenda 2030. ENCONTRO NACIONAL DE PESQUISA EM EDUCAÇÃO EM CIÊNCIAS, XII, Natal, 2019. In: Anais.... Natal: Ed. da UFRN, 2019. Disponível em http://abrapecnet.org.br/enpec/ xii-enpec/anais/resumos/1/R0724-1.pdf. Acesso em 9 set 2020.

SOUZA, R. F.; BORGHI, R. F.; ONOFRE, M. R.; CAMARGO, L. T. Guias curriculares: materiais de orientação docente ou de controle do Estado? R. bras. Est. Pedag, Brasília, v. 80, n. 195, p. 233-243, 1999.

TOZONI-REIS, M. F. C. Metodologia da pesquisa. 2. ed. Curitiba: IESDE Brasil S.A., 2009. 